\title{
An Irregular wide QRS Complex Rhythm
}

\author{
Salvatore Pagano*, Gabriella Aguglia and Massimo Geraci \\ Department of Emergency Medicine, ARNAS Civico-Di Cristina-Benfratelli, Italy
}

Submission: December 14, 2018; Published: January 23, 2019

*Corresponding author: Salvatore Pagano, Dirigente medico, Department of Emergency Medicine, ARNAS Civico-Di Cristina-Benfratelli, Palermo, Italy

\section{Case Report}

There are clearly visible sinus P-waves in the first two beats and in the last one (marked with * in Figure 1). From the third beat an irregular wide QRS complex rhythm with left bundle branch block (LBBB) morphology begins, without visible P-waves. Although the LBBB may suggest a supraventricular rhythm, the

second beat is a fusion complex, revealing a ventricular origin of the wide QRS complex rhythm. On an accurate analysis indeed, the second beat has shorter PR interval and a different QRS morphology compared to the previous one (in DI lead for example it is entirely positive and slightly wider comparing to the previous one which is isodifasic and narrow).

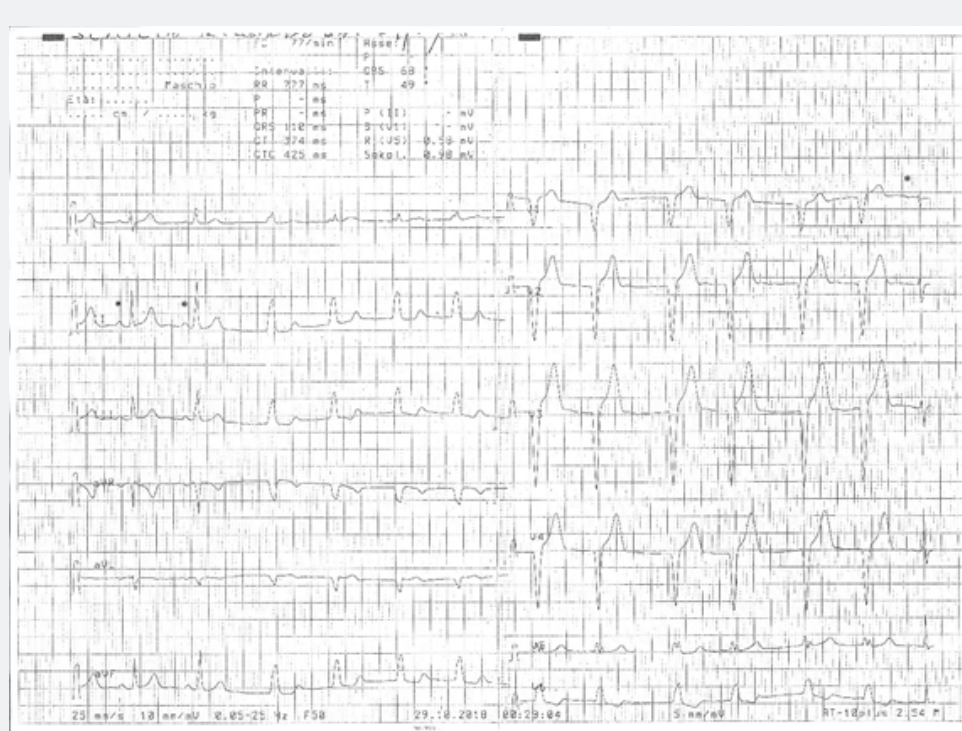

Figure 1: P-waves.

A long strip (Figure 2) clarifies better, showing fusion complexes in the first, third, tenth and fifteenth beats (marked with + ) and Atrio-Ventricular (AV) dissociation in the sixth beat (marked with ${ }^{\wedge}$ ). Hence there are two different pacemakers, one sinus and one ventricular, that coexist and compete each others to depolarize ventricles: as sinus rhythm slows down, ventricular pacemaker appears, until sinus pacemaker increases its rate again. Therefore, this is an accelerated idioventricular rhythm (or idioventricular tachycardia), an arrhythmia due to an enhanced and unprotected ectopic ventricular pacemaker [1] with a rate between 50 and 120 beats per minutes (bpm), then faster than normal intrinsic ventricular escape rhythm, but slower than ventricular tachycardia, that is also influenced by sinus pacemaker, unlike parasystole. It can be seen in healthy patients with no underlying heart diseases but more often it appears after myocardial infarction and it is considered to be a sign of reperfusion [2], with an incidence that is spread since thrombolytic therapy was introduced [3]. It is considered a benign arrhythmia, generally transient, and rarely causes hemodynamic instability due to atrioventricular dissynchrony, requiring treatment (Figure 3).

The peculiarity of this ECG, that makes the diagnosis challenging, is the irregularity of the rhythm, since regularity of $\mathrm{R}-\mathrm{R}$ intervals is considered to be one of the diagnostic criteria of idioventricular rhythms [3]. Irregularity can be explained in this case by vagal tone modulation; another mechanism that had been previously described is Wenchebach exit block [3], but it can be ruled out in this case since R-R intervals don't lengthen progressively until a pause, as instead is seen in this type of 
blocks. Modulation of idioventricular rhythm by vagal tone is a well-known phenomenon and had been previously described in literature [4]. Hence, we suggest that regularity of R-R intervals shouldn't be considered anymore as diagnostic criterion for accelerated idioventricular rhythm.

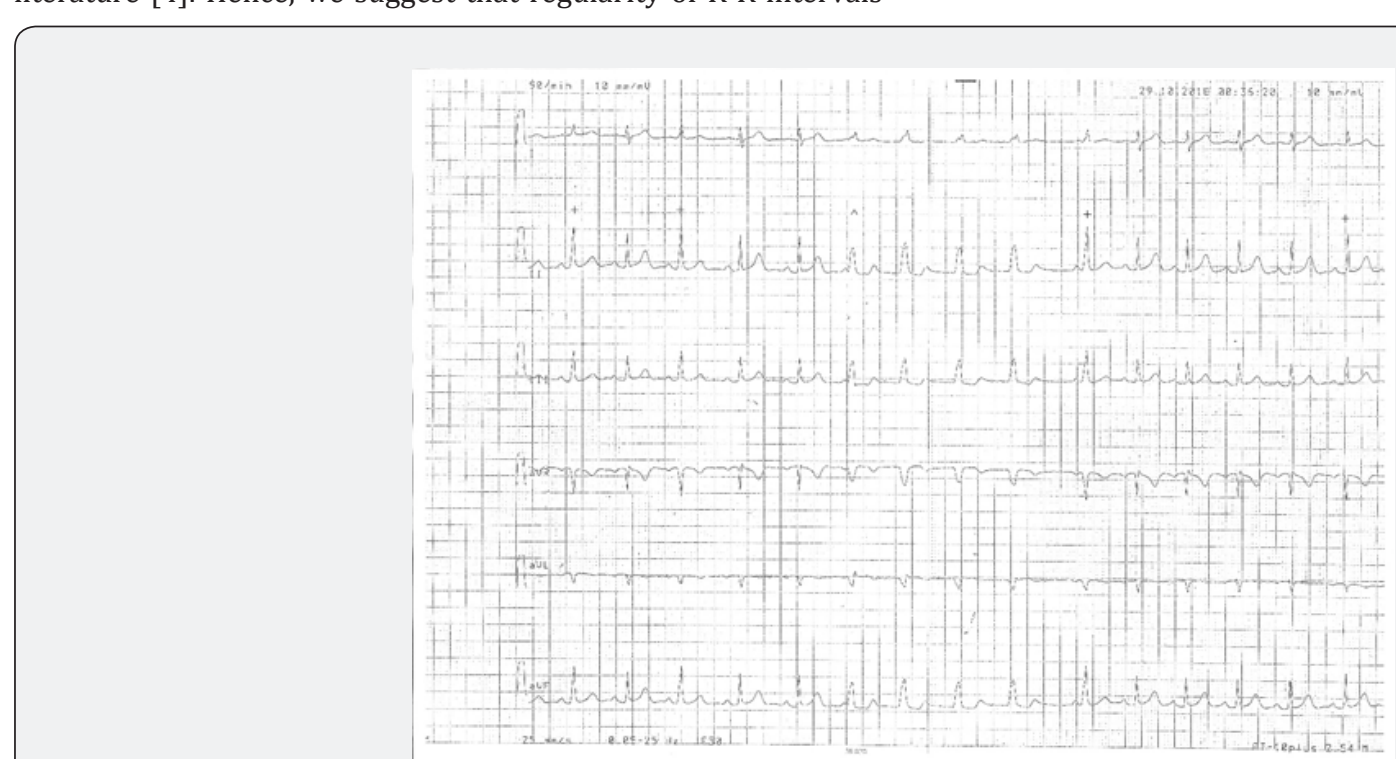

Figure 2

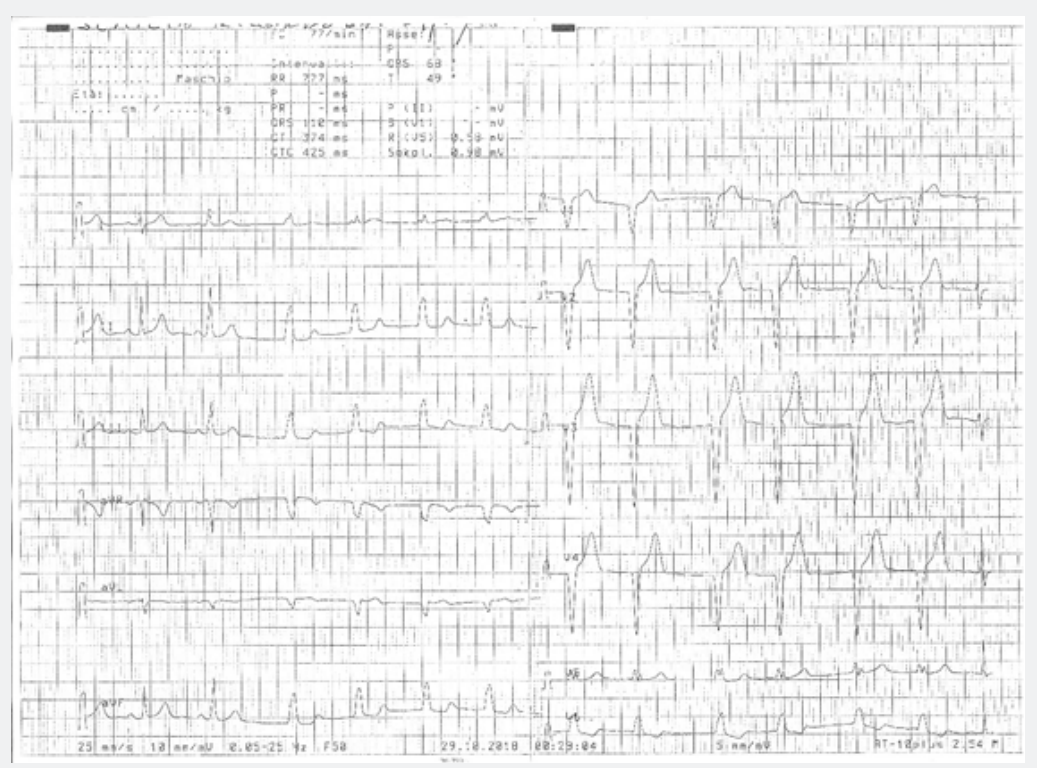

Figure 3

\section{References}

1. Schamroth L (1981) I disordini del ritmo cardiaco. Marrapese, Roma, pp. 139-144.

2. Goldberg S, Greenspon AJ, Urban PL, Muza B, Berger B, et al. (1988) Reperfusion arrhythmia: a marker of restoration of anterograde flow during intracoronary thrombolysis for acute myocardial infarction. Am
J Cardiol 105(1): 26-32.

3. Oreto G (1997) I disordini del ritmo cardiaco. Torino. Centro scientifico Editore, pp. 144-145.

4. Waxman MB, Cupps CL, Cameron DA (1988) Modulation of an idioventricular rhythm by vagal tone. J Am Coll Cardiol 11(5): 10521060. 


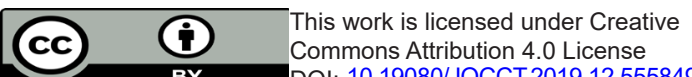

BY DOI: 10.19080/JOCCT.2019.12.555849

Your next submission with Juniper Publishers
will reach you the below assets
- Quality Editorial service
- Swift Peer Review
- Reprints availability
- E-prints Service
- Manuscript Podcast for convenient understanding
- Global attainment for your research
- Manuscript accessibility in different formats
( Pdf, E-pub, Full Text, Audio)
- Unceasing customer service
Track the below URL for one-step submission
https://juniperpublishers.com/online-submission.php

